\title{
Understanding the Dynamics of Green and Blue Spaces for Health and Wellbeing Outcomes in Ireland: A Systemic Stakeholder Perspective
}

\author{
Gesche Kindermann ${ }^{1, *}$, Christine Domegan ${ }^{1}$, Easkey Britton ${ }^{1}$, Caitriona Carlin ${ }^{1}$, Mona Isazad Mashinchi ${ }^{2}$ \\ and Adegboyega Ojo ${ }^{3}$ \\ 1 Whitaker Institute, JE Cairnes Building, National University of Ireland Galway, H91 TK33 Galway, Ireland; \\ christine.domegan@nuigalway.ie (C.D.); hello@easkeybritton.com (E.B.); caitriona.carlin@nuigalway.ie (C.C.) \\ 2 INSIGHT Centre for Data Analytics, National University of Ireland Galway, H91 TK33 Galway, Ireland; \\ mona.isazad@insight-centre.org \\ 3 School of Business, Maynooth University, W23 WK26 Maynooth, Ireland; adegboyega.ojo@nuigalway.ie \\ * Correspondence: gesche.kindermann@nuigalway.ie; Tel.: +353-91-493862
}

check for updates

Citation: Kindermann, G.; Domegan, C.; Britton, E.; Carlin, C.; Isazad Mashinchi, M.; Ojo, A. Understanding the Dynamics of Green and Blue Spaces for Health and Wellbeing Outcomes in Ireland: A Systemic Stakeholder Perspective. Sustainability 2021, 13, 9553. https://doi.org/10.3390/ su13179553

Academic Editor:

Constantina Skanavis

Received: 12 May 2021

Accepted: 10 August 2021

Published: 25 August 2021

Publisher's Note: MDPI stays neutral with regard to jurisdictional claims in published maps and institutional affiliations.

Copyright: (c) 2021 by the authors. Licensee MDPI, Basel, Switzerland. This article is an open access article distributed under the terms and conditions of the Creative Commons Attribution (CC BY) license (https:/ / creativecommons.org/licenses/by/ $4.0 /)$.

\begin{abstract}
Despite the recognised benefits to human health from green and blue spaces, socioeconomic inequalities in access to and use of such spaces have been observed. Using a multidisciplinary, multistakeholder systems approach and structural equation modelling, this paper examines the structural and behavioural dynamics of green and blue spaces, people and health and wellbeing outcomes. Systems thinking offers a deeper understanding of the dynamics of collective choices at all levels within the determinants and the circular causality of these processes. The resulting map shows that behavioural and structural dynamics of green and blue spaces reinforce social cohesion, mental and physical benefits and their circular causality. Acknowledging the importance of multiple uses of green and blue spaces, this paper concludes that delivering universal services at a scale and intensity proportionate to the degree of need is vital to ensure services and health and wellbeing benefits are available to all, not only the most advantaged.
\end{abstract}

Keywords: green and blue space; health and wellbeing; social inequalities; systems thinking

\section{Introduction}

Health and wellbeing, of both individuals and communities, are dependent on a range of determinants including place, i.e., the physical environments in which they live $[1,2]$. 'Healthy places', those places which help promote, maintain and restore good health, are recognised as playing an important role, and there is a growing awareness of the importance of green and blue spaces for health and wellbeing. The United Nation (UN) Sustainable Development Goals (SDGs), recognising the links between green space and human health, explicitly set out to "provide universal access to safe, inclusive and accessible, green and public spaces, in particular for women and children, older persons and persons with disabilities" by 2030. This is based on the acknowledgment of the provision of cultural ecosystem services by green spaces and that these promote human health and wellbeing and, as part of a wider environmental context, have the potential to prevent 'upstream' problems, which is more efficient than dealing with the 'downstream' consequences of ill health and wellbeing [3-13]. There is also increasing interdisciplinary interest in and awareness of the cultural ecosystem services and potential health benefits provided by the use of outdoor water environments or blue spaces [14-22].

While green and blue spaces and health and wellbeing outcomes are linked, these links are complex. The growing body of evidence demonstrates associations (not 'causation') between exposure to green spaces and a variety of human health and wellbeing outcomes [23]. Positive associations have been demonstrated, for example, between residential green spaces and lower all-cause mortality and a reduction of the risk of cardiovascular 
disease [6], improved mental health outcomes and increased feelings of relaxation and restoration [12,24]. Exposure to and use of green spaces is associated with higher rates of physical activity $[12,25]$, which in turn has been shown to be linked to a range of health outcomes including improved cardiovascular health, mental health and neurocognitive development [26]. Increasingly, the role that size, type, quantity and quality of green spaces, perceived attractiveness and accessibility, and level of biodiversity play in promoting human health is being considered. The size of parks used has been shown to be positively associated with participation in physical activity, with users of larger parks being more likely to meet recommended activity levels [27]. Positive mental health has been associated with increased numbers of accessible parks and with parks with a variety of foci, such as recreation, sport and nature [28], while perceived biodiversity of green spaces has been found to be associated with better human health [29]. While proximity to green or blue space does not automatically confer greater access to or use of these spaces, positive healthy living throughout the lifespan benefits from proximity and access to and use of green spaces [30]. A systematic review of 37 studies, mainly carried out in high-income countries demonstrated a statistically significant relationship between healthier birth outcomes and residential greenness [31]. This review and meta-analysis also identified a knowledge gap relating to blue spaces and birth outcomes [31]. Systematic reviews of early childhood health and wellbeing confirmed that children who grow up with more residential green-ness have better physical [32] and mental health [33] though quantity, quality, access and use of these spaces is under-researched. There are positive associations between healthy ageing and exposure to green space [30,34]. Healthy ageing is associated with increased green space, for example, increased physical activity [35]. Urban greenery promoted walking [36] and benefited the activities of daily living [37] in older people. Increased residential greenness is also associated with decreased levels of diabetes [38] in older people. A recent systematic review of physical activity and environmental features emphasised the importance of accessibility and overcoming physical barriers [39]. Similarly, perceptions regarding access and safety were important considerations for older people [40], but their study also showed that green spaces are attractive from an aesthetic perspective. However, it needs to be considered that associations between human health and green spaces throughout the lifespan tend to vary with socioeconomic status, gender and ethnicity. As is the case for green space, evidence of direct causation is limited, but research findings highlight positive associations between various dimensions of human health and wellbeing and blue space. In particular, positive associations have been demonstrated between residential blue space and improved mental health outcomes [15], reduced psychological distress [41], increased recreational use [15,42,43], preference, affect and restorativeness [4,42], strong associations with giving meaning to place [44], and greater social connectedness [19]. Water quality has been found to impact health: high-quality waters reduce the potentially harmful contaminants and also increase the time that recreationists spend engaged in a water-based activity; polluted sites have a negative effect on perceived restorativeness and sense of wellbeing $[45,46]$. Specific interest in blue space has grown alongside recognition of the need for greater protection and adaptation in response to climate change (e.g., flood control and storm surge responses) [47,48]. Research in Finland emphasises 'fair blue urbanism' and the need to consider the sociodemographics of those who access and use blue space [49]. A study in the UK found that the health benefits of blue space increased in lower socioeconomic areas [22]. Unwanted trade-offs such as the risk of increasing socioeconomic inequalities when developing blue space areas (e.g., high property value of waterfront areas) cannot be ignored [50,51]. The literature also highlights that proximity to blue space does not necessarily equate with access to or use of that space [50]. Access to green and blue spaces is a question of analysing interdependencies and patterns of system behaviours.

Despite the recognition of health benefits from green and blue spaces, a socioeconomic gradient in inequalities in access to green spaces has been demonstrated [52]. Just as the burden of environmental and health hazards [53] has mainly fallen on people living in 
marginalised communities or who themselves are marginalised [54], unequal access to green and blue spaces is now recognised as an environmental equity issue [53,55]. Advocacy for increased provision of green and blue spaces in marginalised neighbourhoods has resulted in the unintended consequence of 'gentrifying' an area [56]. Research in the US confirms that this can make property and living costs prohibitive [57], thus further displacing or disabling access to green and blue spaces for minority and marginalised groups $[57,58]$. Equitable green space provision can be achieved if communities are engaged [59], and there are clearer policies regarding location, size, management, access and use [60].

Inequality in relation to access to outdoor spaces is a type of spatial inequality. Spatial inequalities contribute to social inequalities, which themselves give rise to health inequalities. The mechanisms for the interactions between green and blue spaces and health and wellbeing inequalities are unclear: new approaches using qualitative and quantitative methods are needed. There is an obligation to think beyond the discrete influence of particular contextual factors and to consider the connectedness of those factors. Managing health requires a whole systems perspective [61], and understanding and addressing the complex relationships between places, green and blue spaces and health requires complex systems thinking [62-64].

While the relationship between green and blue spaces and human health is complex in all countries, understanding of the dynamics of this relationship and levels of information and data on health and wellbeing and access to green and blue spaces varies. In Ireland, these dynamics are not fully explored, and information relating to access to and multiple uses of green and blue spaces are piecemeal at best, with health data in particular being limited due to limited resources and data privacy legislation restrictions [65]. Existing research however confirms for example, that in Ireland, increased use of green spaces is related to better health and increased provision of attractive visitor facilities increases use [66], and exposure to coastal blue space has been shown to decrease depression in adults [67]. Furthermore, in 2019 and 2020, the majority of survey respondents agreed that local green spaces were within walking distance and accessible, although lack of public transport was identified as an issue albeit without being considered a main barrier to accessing green and blue spaces [68]. However, evidence also indicates that there are links between the availability and use of green and blue spaces and socioeconomic determinants of health and wellbeing in Ireland, and that there is a regional and urban/rural divide in Ireland in relation to green and blue spaces, health outcomes and their socioeconomic determinants $[67,68]$. With a growing recognition of the importance of green and blue spaces for health and wellbeing comes a growing need to understand the relevant structural and behavioural dynamics in Ireland.

A complex systems approach (e.g., agent modelling or community modelling) improves understanding and decision-making capabilities [69]. However, many emerging systems models are agent or expert based [61]. Here, we answer the call for multidisciplinary, stakeholder-engaged studies [69]. To develop a rich picture from different perspectives, we use a multidisciplinary, stakeholder-engaged approach to investigate the dynamics between green and blue spaces, people and health and wellbeing outcomes, with a particular focus on accessibility and usage, and how these are influenced by place in Ireland. The contribution of this paper lies in an effort to address the gap between (1) understanding complex interactions between place, green and blue spaces and health and wellbeing and (2) describing its complex dynamics. The study aims to explore the key forces and patterns at work in relation to access to green and blue spaces in Ireland. In contrast to simulation-based system dynamics, we employ a 'softer' and qualitative methodological approach to addressing health and space. Specifically, we do not build a formal computer simulation model-we rely mostly on what Wolstenholme [70] (p. 424) characterises as causal loop qualitative system dynamics, marking its "significant level of assistance" in issue structuring and problem solving. 


\section{Materials and Methods}

\subsection{Green and Blue Spaces Defined}

In relation to health and wellbeing research, natural environments tend to be broadly divided into green and blue spaces. The definitions of green space (or greenspace) are varied, with different organisations, institutions and research groups using different interpretations. Definitions also overlap, with terms such as 'public spaces', 'urban spaces', 'open spaces' and 'green spaces' often used interchangeably within the literature, with many encompassing blue spaces. Based on definitions and the recommendation from Taylor and Hochuli [71] that a researcher should construct a definition of green space for the context of their research that utilises both qualitative and quantitative aspects, and on the need to separate green and blue space, the need to include both urban and rural areas, and given the focus of the study on health and wellbeing, green space is used to refer to all terrestrial outdoor, natural or semi-natural surfaces or settings or features with potential for the promotion of human health and wellbeing.

While they are separate, blue space is often assumed under the umbrella concept of green space or green infrastructure where the assumption is that these spaces "improve environmental conditions and therefore citizens' health and quality of life" [72]. Definitions of blue space in the literature are limited. Studies that include a definition largely define blue space to include all visible outdoor surface waters $[4,16]$. For this project, blue space is defined as all visible, outdoor, natural or man-made surface waters with potential for the promotion of human health and wellbeing.

The focus on accessible green and blue spaces, as defined above, excludes private spaces, such as gardens and those for which entrance fees need to be paid. The Natural England nearby Nature guidance document offers the following definition: "Accessible spaces are spaces that are available for the general public to use free of charge and without time restrictions (although some sites may be closed to the public overnight and there may be fees for parking a vehicle)" [73]. These are spaces that are available to everyone, meaning all reasonable efforts are made to fulfil the requirements under the UK Disability Discrimination Act 1995. Accessible spaces are also known to their target users, including potential users, living within the catchment of that space; active and potential users are aware of these spaces.

\subsection{System Dynamics Assessment}

Utilizing the green and blue definitions above, the research methodology is grounded in systems thinking and behavioural science in an Irish context [74]. The methodology adopts a collective intelligence, group model building and soft systems approach, making extensive use of multistakeholder engagement to identify and map the feedback relationships [75-77] between the socioeconomic, environmental, health and wellbeing system elements. The four-stage methodology (Table 1) concentrates on the "complex social networks of individuals and groups linked through shared participation in the creation and delivery of .... the perceived quality of life" [78] (p. 305).

In phase one, an extensive literature review identified relevant forces that have been shown to influence people's access to and use of green and blue spaces for their health and wellbeing. This was supplemented by collection of primary data from multilevel multidisciplinary key informant stakeholder interviews (KISIs) $(n=27)$ and group interviews $(n=20)$ who identified and listed their barriers and enablers to the access to and use of green and blue spaces. A total of 221 barriers and 118 enablers were identified. Phase one concluded with the development of study protocols in relation to construct and operational definitions of key green and blue variables. 
Table 1. Overview of the 4-phase methodological approach taken including research samples, data collection agents, outcomes and timeframes.

\begin{tabular}{|c|c|c|c|c|c|}
\hline Phase & Activity/Method & Sample & $\begin{array}{c}\text { Data Collection } \\
\text { Agent }\end{array}$ & Outcome & Timeframe \\
\hline \multirow{3}{*}{ Phase 1} & $\begin{array}{l}\text { Literature review for } \\
\text { barrier/enabler } \\
\text { identification }\end{array}$ & $\mathrm{n}=450$ & $\begin{array}{l}\text { performed by } \\
\text { researchers; }\end{array}$ & \multirow{3}{*}{$\begin{array}{l}\text { a list of system barriers } \\
(\mathrm{n}=221) \text { and system } \\
\text { enablers }(\mathrm{n}=118)\end{array}$} & 3 months \\
\hline & Group interviews & $\begin{array}{l}\mathrm{n}=20 \text {, incl. local } \\
\text { governance, data, } \\
\text { health promotion, } \\
\text { green/blue snace }\end{array}$ & group work; & & a series \\
\hline & $\begin{array}{c}\text { Key informant } \\
\text { stakeholder interviews } \\
\text { (KISIs) }\end{array}$ & $\begin{array}{c}\mathrm{n}=27, \text { incl. } \\
\text { green/blue active } \\
\text { users and nonusers, } \\
\text { community group and } \\
\text { organisation reps. }\end{array}$ & $\begin{array}{l}\text { performed by } \\
\text { researchers }\end{array}$ & & a series \\
\hline \multirow{3}{*}{ Phase 2} & $\begin{array}{l}\text { Group model building } \\
\text { system mapping }\end{array}$ & $\begin{array}{c}\text { system barriers } \\
(\mathrm{n}=221) \text { and system } \\
\text { enablers }(\mathrm{n}=118)\end{array}$ & $\begin{array}{l}\text { performed by a } \\
\text { modelling group } \\
\quad(\mathrm{n}=8)\end{array}$ & \multirow{3}{*}{$\begin{array}{c}36 \text { themes } \\
\text { a system map and its } \\
\text { narrative; } \\
\text { causal feedback loop } \\
\text { narratives }(\mathrm{n}=7)\end{array}$} & \multirow{3}{*}{$\begin{array}{c}2 \text { months (8 } \\
\text { modelling } \\
\text { sessions) } \\
\text { during all } \\
\text { modelling } \\
\text { time (incl. } \\
\text { Phases 3-4) }\end{array}$} \\
\hline & & & & & \\
\hline & $\begin{array}{l}\text { Modelling software } \\
\text { use (Kumu software) }\end{array}$ & single feedback loops & $\begin{array}{l}\text { performed by } \\
\text { researchers }\end{array}$ & & \\
\hline \multirow[t]{2}{*}{ Phase 3} & $\begin{array}{l}\text { Key informant } \\
\text { interviews }\end{array}$ & $\begin{array}{c}\mathrm{n}=18 \text {, incl. health and } \\
\text { health promotion, } \\
\text { data, green/blue } \\
\text { space, governance }\end{array}$ & $\begin{array}{l}\text { performed by } \\
\text { researchers }\end{array}$ & a socialised map; & $1 \mathrm{~h}$ each \\
\hline & $\begin{array}{l}\text { Socialisation of system } \\
\text { mapping }\end{array}$ & Public events $(n=2)$ & $\begin{array}{l}\text { performed by a } \\
\text { modelling group } \\
\qquad(\mathrm{n}=4)\end{array}$ & an updated map & 1 month \\
\hline Phase 4 & $\begin{array}{l}\text { SEM testing } 4 \text { dynamic } \\
\text { hypotheses }\end{array}$ & $\begin{array}{c}\text { Nationally } \\
\text { representative survey } \\
(\mathrm{n}=1007)[65]\end{array}$ & $\begin{array}{l}\text { performed by } \\
\text { researchers }\end{array}$ & $\begin{array}{l}4 \text { dynamic hypothesis } \\
\text { for SEM testing } \\
3 \text { hypotheses } \\
\text { supported; } 1 \\
\text { hypothesis } \\
\text { unsupported. }\end{array}$ & 3 months \\
\hline
\end{tabular}

Phase two consisted of a multidisciplinary model building team $(n=8 ; 2$ public health, 2 data analytics, 3 green/blue space and 1 systems experts) using paired comparison to generate barrier and enabler categories into 36 themes. Perceived causes and effects were analysed, and causal loops were created to build the overall systems map (Figure 1). During the second phase, the dynamic relationships between the stakeholder, behavioural and structural and barriers and enablers were identified. The tasks included:

1. analysis of the system-affecting barriers and grouping them into barrier themes/categories, categorised as behavioural barriers or system structure forces.

2. development of the narratives of these barriers and enabler themes via individual feedback loops;

3. connection of individual feedback loops into a qualitative systems dynamic map; and

4. identification of the dominant dynamics that explain the people's behaviours and their access to and use of green and blue spaces. 


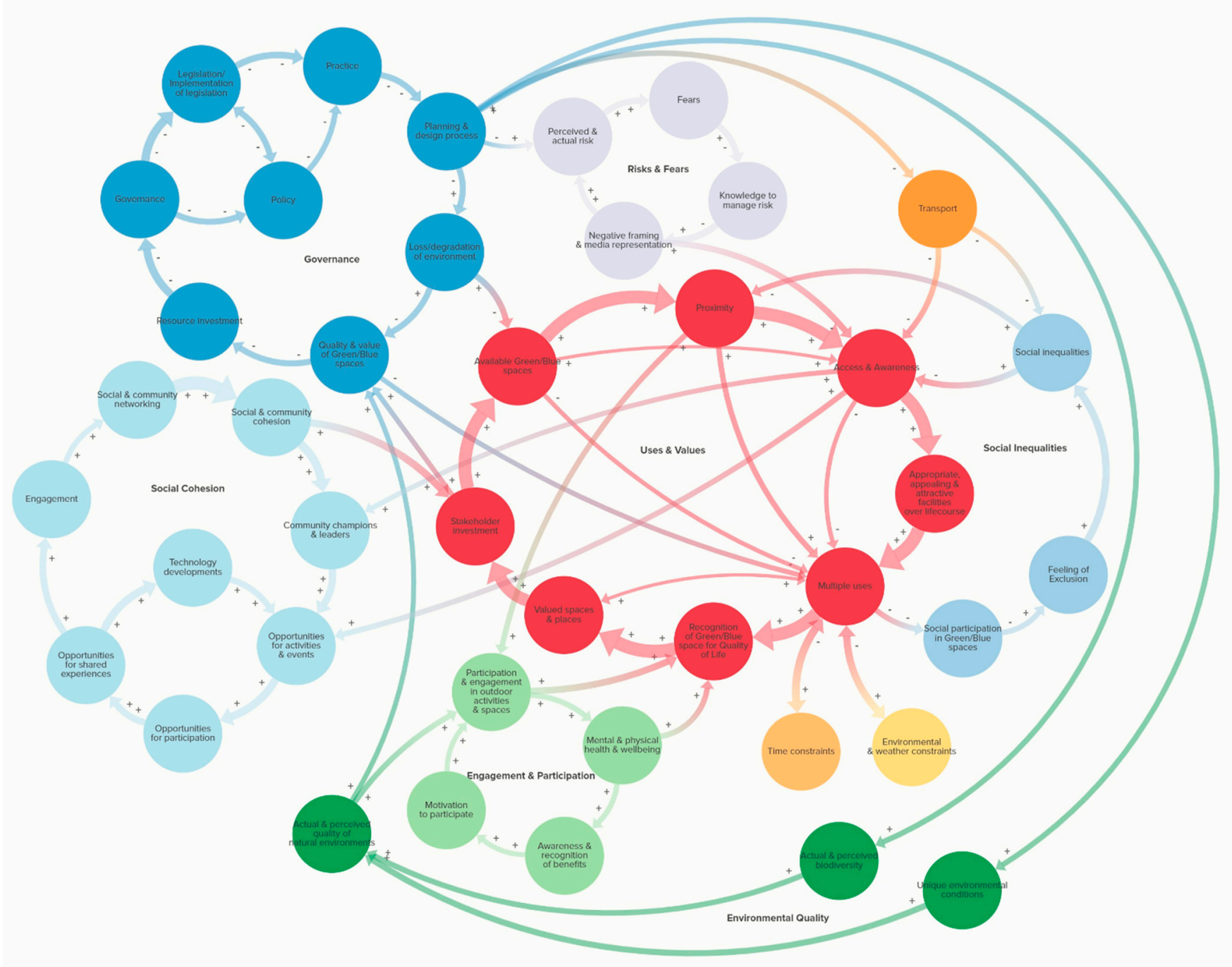

Figure 1. The forces and patterns currently at work in relation to the socioeconomic determinants, health and wellbeing outcomes and access to green and blue spaces in Ireland.

This resulted in the generation of an initial multicausal qualitative green and blue spaces systems map, depicting the interactions between the socioeconomic, health, wellbeing, and environmental elements that inhibit and/or enable access to blue/green spaces in Ireland. The map was originated with the help of Kumu software, a visualisation platform for mapping systems and causal relationships [79]. This software does not strictly adhere to the traditional design of causal loop diagrams applicable in system dynamics. It allows the simultaneous use of " + " and " -" polarity signs on the same causality-marking arrow. For instance, two " + " signs on a single arrow means a causal link between two variables, where a change occurs in the same direction. When different polarity signs are used on a single arrow, it means opposite direction of causality.

In phase three, once the map was built and the narrative was developed, the map and narratives were reviewed with all macro-, meso- and micro-stakeholders $(n=18)$ (Table 1$)$ for feedback, triangulation and verification, and relevant changes were made following the socialisation of the map. This resulted in a qualitative systems dynamic map, depicting seven underlying causal loops of barriers and enablers in relation to green and blue space usage (Figure 1 below).

Phase four included structural equation modelling (SEM) to test the internal logic and confirm, or not, the validity of the systems dynamic map and dominant dynamics, specifically hypotheses relating to social inequalities and green and blue space access and 
usage in Ireland [61,69]. The SEM used responses $(n=1007)$ from another study [65] that included a nationally representative survey on green and blue spaces in Ireland carried out in 2019, and the following hypotheses were tested:

Hypothesis 1 (H1). Health is influenced by multiple use of blue/green spaces.

Hypothesis 2 (H2). Socioeconomic determinants determine multiple use of blue/green spaces.

Hypothesis 3 (H3). Access determines the multiple uses of blue/green spaces.

Hypothesis 4 (H4). Socioeconomic determinants determine access to blue/green spaces.

\section{Results and Discussion}

\subsection{System Dynamics Assessment}

The resulting map (Figure 1) enables a visualisation of all the perceived dynamics currently at play in relation to the use of green and blue spaces for health and wellbeing in Ireland. It captures the interacting factors and incorporates diverse perspectives, experiences and structural issues. It captures the micro individual variables, the macro organisational and structural elements together with their interactions. It identifies the complex, diverse dynamic interconnections between the forces. The map presents core forces that currently block (act as barriers) or promote (act as enablers) health and wellbeing in the system. An example of an enabler is 'Social and Community Cohesion', which, together with other enablers forms a positive feedback or 'virtuous' loop. Some of the barriers form negative feedback loops. For example, risks and fears, which is an example of a 'vicious loop'.

The interconnected forces and factors identified in this systems map are:

- Uses and values of green and blue spaces

- Social inequalities

- Social and community cohesion

- Risks and fears

- Participation and engagement

- Biodiversity quality and value

- Governance

The map identifies 'Uses and Values of Outdoor Spaces' as the dominant dynamics that underpin the map. Then, there are two dominant and interconnected themes. One theme relates to governance, and the second theme relates to social cohesion and stakeholder value.

Uses and Values of Outdoor Spaces: The amount of outdoor spaces that are nearby and accessible, with appropriate and attractive facilities, for individuals, groups and communities across the lifecourse determines their uses, including physical, recreational, conservation and cultural uses. 'Multiple uses' is about the variety of spaces, facilities, and activities. 'Multiple uses' is also about the repeated use of these spaces by individuals, groups and communities. When outdoor spaces are used by different individuals, groups and communities, benefits occur. These are health, social, community, cultural, environmental, economic and wellbeing benefits, which all impact on quality of life. When users and others (e.g., local authorities, policy makers and health promoters) value and appreciate these quality of life benefits, outdoor spaces are invested in, increasing the amount and quality of these spaces. Time: Perceived and actual lack of time limits the uses of outdoor spaces: the less we use an outdoor space, the less time we make for its use. Environmental and Weather Conditions, which are perceived as adverse, limit the uses of outdoor spaces. When different users are restricted in their use of outdoor spaces, user perceptions of environmental and weather constraints increase. Transport is directly linked to access to green and blue spaces and social inequalities. Insufficient transport infrastructure reduces access to green and blue spaces in particular for those who rely on public transport for access. 
Social Inequalities strongly influence and determine access to and use of green and blue spaces. Social inequalities include disparities relating to health, socioeconomic status, employment, education, race, gender, housing quality, car ownership, minority and relationship status but also relate to community wellbeing. At a population level, social inequalities are measured by the Irish Pobal deprivation index. A higher deprivation index shows greater social inequalities. Awareness of and access to outdoor spaces decrease with increasing social inequalities. Proximity to outdoor spaces decreases with increasing social inequalities. Awareness, access and proximity determine the uses of outdoor spaces, social participation in green and blue spaces and feelings of exclusion, which reinforce social inequalities. The use of outdoor spaces is also determined by perceived and actual lack of time.

Social and Community Cohesion benefits from green and blue spaces that are available and accessible. With increasing outdoor spaces that are available, accessible and appropriate, there are more community champions and leaders who help create opportunities for activities and events in these outdoor spaces. Opportunities for social and community participation and shared experiences are increased. Technology developments enhance opportunities for activities and events, opportunities for social and community participation and shared experiences. These promote engagement, social and community interactions, networking, and social and community cohesion.

Risks and Fears: Negative framing and narratives, including news and media reports, myths, stories and cultural norms, influence how people and communities perceive risks associated with outdoor spaces. Perceived and actual risks create and enhance fears associated with outdoor spaces. A lack of knowledge on how to manage the perceived and actual risks and fears feeds negative narratives.

Participation and Engagement in outdoor activities and spaces delivers physical and mental health and wellbeing benefits. Awareness and recognition of these benefits motivates individuals, groups and communities to participate and engage in using outdoor spaces. Participation and engagement are also influenced by proximity.

Biodiversity and Natural Environments: Biodiversity is about the abundance, variety and diversity of plants and animals in nature. Biodiversity (actual and perceived) shapes our perceptions of the quality of natural environments and participation and engagement in outdoor spaces. Ireland's unique environmental and cultural conditions (e.g., temperate climate, waves, and dark skies) shape our perceptions of the quality of natural environments, and participation and engagement in outdoor spaces. It also delivers cultural (including recreational) and economic benefits (e.g., Ireland's Wild Atlantic Way tourism initiative). Awareness and recognition of these multiple benefits adds to how these spaces and places are valued by individuals, groups, communities and society. When the value of these spaces is recognised, individuals, groups, communities and society use them more. With increasing quality, the value and the amount of green and blue spaces increase.

Governance is about legislation, legislative implementation and policies. Poor policies, insufficient legislation and implementation lead to poor practices. This reinforces poor planning and design processes, including insufficient transport, and can increase perceived and actual risk in relation to outdoor environments. Poor planning and design increase environmental loss and degradation, limiting the amount and quality of, access to and usage of outdoor spaces. It also drives the lack of resources and investment in green and blue spaces, decreasing their value.

\subsection{Dominant Dynamics and Clarity of Change}

The iteration of reflecting and analysing the detail from the literature review in phase one to the individual feedback loops and map in phase two gives the multidisciplinary model building team and participating stakeholders' clarity and a much richer understanding as to the collective health and wellbeing benefits possible from green and blue spaces. The multidisciplinary model building team are also able to explain the contradictions between the different communities who access and use or do not access and use, green 
and blue spaces. The group clarity around what to change generates alignment between the individual models, synthesizing the diversity of individual expert and stakeholder points of view. At the beginning of the case study, based on the literature review findings, members of the multidisciplinary model building team believed more access to green and blue spaces would increase health and wellbeing benefits. After the study, all members appreciated the detailed and dynamic complexity surrounding usage as well as access, including the dominant role of beliefs, perceptions and myths. It allows for constant system-improving outcomes of concurrent and adaptive refinement (assisted by visualised and collectively created mental models of the system), rather than intervention outputs, which are often one dimensional and short lived.

The multidisciplinary model building team's iterative and participatory activities of learning about green and blue space dynamics requires much practice, patience, psychological empathy and time, with a simultaneous consideration of procedural rigor and strict adherence to the study protocols. The group were aware that any deviations from the study protocols might have impinged upon the results. This also extended to the time given to the correct representation of the system by mapping, selecting and engaging system stakeholders.

\subsection{Structural Equation Modelling}

With a goodness-of-fit (GFI) of 0.851 and a model chi-square value of 1225.401 $(\mathrm{df}=131.00, p$ value $=0.000)$, one of the models supported three of the four hypotheses (H1-H3). This indicates that health is influenced by multiple use, including both repeat use and diversity of use, of blue/green spaces (H1). Multiple use is determined by socioeconomic determinants $(\mathrm{H} 2)$ and by access $(\mathrm{H} 3)$. The final hypothesis $(\mathrm{H} 4)$ was not supported by the model. The socioeconomic determinants included in this model are level of education, income and employment. Access variables included are the ease of access to local green and blue spaces, while multiple uses include the diversity of activities carried out together with reasons for visit. Health variables included in this model were taken from the energy and vitality index (EVI).

Another model, with a slightly lower GFI of 0.847 and a model chi-square value of $1348.321(\mathrm{df}=148.00, p$ value $=0.000)$ proved the same three hypotheses $(\mathrm{H} 1-\mathrm{H} 3)$. The fourth hypothesis, setting out that socioeconomic determinants determine access to green and blue spaces, was again not supported. The variables included in the second model are the same as the first, with the only change being in the health variables, which also included self-reported health. A final model with a GFI of 0.924 and a model chi-square value of $605.117(\mathrm{df}=115.00, p$ value $=0.000)$ included $\mathrm{BMI}$ as an additional health variable instead of self-reported health. This model again supported three of the four hypotheses (H1-H3), while the last hypothesis (H4) was not supported.

The SEM supported three of the four hypotheses, indicating that in Ireland, health is influenced by multiple use, including both repeat use and diversity of use, of green and blue spaces (H1), i.e., the more green and blue spaces are used by different individuals, groups and communities, the better the health of these individuals, groups or communities. Multiple use in turn is determined by socioeconomic determinants (H2); therefore, uses of green and blue spaces decrease with increasing levels of socioeconomic inequalities and by access to green and blue spaces (H3). These findings endorse the dominant structure of the systems dynamic map. The final hypothesis $(\mathrm{H} 4)$ was that socioeconomic determinants determine access to green and blue spaces; however, this was not supported. This indicates that in Ireland, socioeconomic determinants, as such, do not define access to green and blue spaces.

\subsection{Integrated Interventions Possibility}

The post-COVID-19 world is shaped increasingly by collective as well as individual choices. Systems thinking and behavioural sciences offer a deeper understanding of the dynamics of collective choices at all levels within the sociodeterminants that connect 
individuals, communities, stakeholders and policy makers. A deeper understanding of the behavioural and structural dynamics, that goes beyond the almost exclusively based self-reported survey responses lacking ecological validity and generalisability, to capture a far more complex, realistic and "noisy" understanding is essential for strengthening the relevance of health and place to management and policy making [80,81]. Systems create different outcomes as a whole compared to those created by individuals acting alone [82]. This deeper understanding of these systems and their dynamics may help move communities towards healthy lifestyles. For example, individuals come to the system with their own background, and that respective background influences their health and place interactions within the system. The actions and reactions of individuals in one context are influencing the actions and reactions in others as the process of coevolution takes place. Theoretically, systems evolve towards equilibrium via interactions and exchanges between unequal participants $[78,83,84]$. In practice, systems have a multiplicity of stakeholders with different agendas, with health and place outcomes that are the result of the interplay between macro-, meso- and micro-forces that are dynamically interdependent on the systemic environment [85]. As pointed out by Wilson [86] (p. 286), "evolutionary theory distinctively identifies the small group as a fundamental unit of human social organization, required for both individual well-being and effective action on a larger scale". The dynamics of collective choice in a system are not simply the product of individual aggregation or linear causality but dependent on the continuing interaction of multilevel stakeholder groups based on circular causality [87].

The systems map (Figure 1) is an innovative and engaging tool for the multidisciplinary model building team, socialisation and stakeholder conversations around possible solutions, options and leverage points. The multidisciplinary model building team participants and stakeholders can see the system before placing themselves in that system. For the majority, this is their first experience of a systemic or holistic picture of the system they are working in on a daily basis. It is important the map is complex enough to capture what is happening in the system but not so complex that it is not comprehendible by stakeholders who are not part of the multidisciplinary model building team. A complex but not too complex map avoids map shock and is valuable to the design stage of an intervention, turning the map into a co-design tool that allows all of the stakeholders to engage with potential change from a bottom-up and top-down process.

Synthesizing all the suggested solutions, activities and options creates integrated interventions that are multilevel and multistakeholder in nature, and more likely to engage individuals and communities avoiding green and blue space usage, promoting health and wellbeing benefits. The communication with and involvement of various stakeholders in the consensus-based elicitation of these stakeholders' knowledge of possible solutions, together with their cocreated top-down and bottom-up buy-in to a new-shared future lies at the core of dynamic techniques. When all stakeholders are involved in the modelling process, this engages in the coproduction of findings, which employ crucial kinds of lived expertise that make results more relevant and practical and increase the probabilities of an intervention being successful to promote overall health and wellbeing. Managing green and blue space environments, communicating with stakeholders and promotion of health and wellbeing require a whole systems perspective, which is being presented here. A systems approach improves understanding and decision-making capabilities, creating a positive feedback between policies designed to enhance environments and ecosystem services, policies for local green and blue space management and health promotion.

The map with its integrated solutions is a valuable tool to communicate and introduce new stakeholders, new space managers or decision and policy makers that need initial insight into health and place. The dynamic and detailed knowledge is not lost with staff rotation. Capacity building can continue through the simplification of the presented narratives. Furthermore, the multidisciplinary model building team working time in phase one, given to how some definitions from one domain (e.g., health) may have different meanings in another (e.g., outdoor activities) is central to progress. Construct and opera- 
tional definitions of key variables as part of phase one significantly aid multidisciplinary model building team and interdisciplinary understanding of a complex issue such as health and place.

\subsection{Limitations and Further Research}

This is a qualitative study to examine how national and regional access to green and blue spaces influences health and wellbeing; it applied a systems-thinking approach to the dynamics surrounding the use of green and blue spaces, supported by currently available data. To date, data relating to the multiple uses (including physical, recreational, conservation and cultural uses) of green and blue spaces, across the lifespan, in Ireland is piecemeal. Gathering and sharing of relevant data and information by various macro and meso health and environmental institutions is required to provide further evidence and strengthen the knowledge base for decision making and improved access to green and blue spaces in Ireland. It is only with population-to-local level usage spatial data that the social and health inequalities which segments of society experience, and the social and community cohesion that other individuals and communities benefit from, can be understood and ultimately managed for in policies and practice.

Further construct and operational definitions of key green and blue variables and monitoring is required. Importantly, the power, tensions and conflicts between macro-, meso- and micro-stakeholders require further delineation. Lastly, this research did not focus on the implementation of the leverage points or their evaluation and monitoring, though many stakeholders made suggestions as to how to improve the dynamics in relation to the socioeconomic determinants, access to and multiple uses of green and blue spaces.

Understanding the structural and behavioural dynamics of a system over time and identifying ways to disrupt, change or unlock it do not automatically lead to integrated interventions. Collective intelligence and consensus-based methods for co-design and cocreation of interventions are of importance as is an understanding the dynamics of complementary, adjacent and competitive systems. In relation to spatial and health inequalities, there is a justification for understanding the system dynamics of access to and use of green and blue spaces in Ireland as they are clearly embedded within this. In practice, funding, resources and time available to the decision or policy maker may mitigate against doing such broader systems analysis and mapping.

Finally, the qualitative dynamics mapping undertaken in this case study could be followed by or replaced with quantitative modelling, using further tools from systems dynamics, such as pathway participation metrics [88].

\section{Conclusions}

Taking a multistakeholder systems approach, stakeholders with relevant knowledge collectively developed a systems dynamic model of the current situation in relation to the dynamics of green and blue spaces for health and wellbeing in Ireland. The systems map was supported by SEM using available existing data, which confirmed that in Ireland, people's health and wellbeing are determined by multiple use of green and blue spaces, which in turn is determined by access to green and blue spaces and socioeconomic determinants. Therefore, socioeconomic inequalities have an impact on health in Ireland. The distribution of green and blue spaces also contributes to spatial and environmental inequalities, which are linked to socioeconomic determinants, multiple use and health. Overall, the map demonstrates to stakeholders, decision makers, and policy and programme managers that a sustainable green/blue strategy with healthy outcomes for individuals and communities requires a systemic perspective. This perspective needs to account for both individual and structural factors over the lifecourse.

With UN SDGs and the Right to Health (Universal Declaration of Human Rights, 1948; International Covenant on Economic, Social and Cultural Rights, 1968) in mindplanners, policy makers, practitioners, and researchers have a duty of care to move away from a reductionist top-down approach to green and blue spaces. The movement is 
towards a holistic, polycentric and complex understanding of the interconnected context of place, green and blue spaces for health outcomes [89-91]. There is an obligation to think beyond the discrete influence of particular contextual factors and to consider the connectedness of those factors. Use of green and blue spaces is a question of understanding interdependencies and patterns of space and wellbeing.

Having communities of people understand the green and blue space interdependencies affecting their mental and physical health may ensure that they are vocal in communicating and questioning the role of these interdependencies in planning, housing, biodiversity, etc., as there is recognition that no one green and blue solution is necessarily the "right" solution. Instead, the diversity and heterogeneity of green and blue spaces demands fairness and equality for the collective and individual good. Faced with a growing range of health and social problems the challenge for practitioners, policy- and decisionmakers now lies in identifying sustainable opportunities to integrate nature and human health without causing further inequality. Proportionate universalism (the resourcing and delivering of universal services at a scale and intensity proportionate to the degree of need) ensures services are available to all, not only the most advantaged, and are able to respond to the level of need.

Author Contributions: Principal investigator: C.D.; system dynamics assessment: G.K., C.D., E.B. and C.C.; structural equation modelling: M.I.M. and A.O.; visualisation: G.K.; writing: G.K., C.D., E.B. and C.C. All authors have read and agreed to the published version of the manuscript.

Funding: This research was funded the Environmental Protection Agency (EPA) Ireland.

Institutional Review Board Statement: The Sheer Wellbeing project was approved by the Institutional Ethics Committee of the National University of Ireland (R19.Mar.18. and 20 March 2019).

Informed Consent Statement: Informed consent was obtained from all subjects involved in the study.

Data Availability Statement: Data utilised for the SEM was gathered as part of the Sheer Wellbeing Project [65].

Conflicts of Interest: The authors declare no conflict of interest.

\section{References}

1. World Health Organization. Health21: The Health for All Policy Framework for the WHO European Region; World Health Organization, Regional Office for Europe: Copenhagen, Denmark, 1999.

2. World Health Organization. Review of Social Determinants and the Health Divide in the WHO European Region; WHO Regional Office for Europe: Copenhagen, Denmark, 2013.

3. Martin, L.; White, M.P.; Hunt, A.; Richardson, M.; Pahl, S.; Burt, J. Nature contact, nature connectedness and associations with health, wellbeing and pro-environmental behaviours. J. Environ. Psychol. 2020, 68, 101389. [CrossRef]

4. White, M.P.; Alcock, I.; Grellier, J.; Wheeler, B.; Hartig, T.; Warber, S.L.; Bone, A.; Depledge, M.H.; Fleming, L.E. Spending at least 120 minutes a week in nature is associated with good health and wellbeing. Sci. Rep. 2019, 9, 7730. [CrossRef] [PubMed]

5. Twohig-Bennett, C.; Jones, A. The health benefits of the great outdoors: A systematic review and meta-analysis of greenspace exposure and health outcomes. Environ. Res. 2018, 166, 628-637. [CrossRef]

6. Gascon, M.; Triguero-Mas, M.; Martínez, D.; Dadvand, P.; Rojas-Rueda, D.; Plasència, A.; Nieuwenhuijsen, M.J. Residential green spaces and mortality: A systematic review. Environ. Int. 2016, 86, 60-67. [CrossRef]

7. James, P.; Hart, J.E.; Banay, R.F.; Laden, F. Exposure to Greenness and Mortality in a Nationwide Prospective Cohort Study of Women. Environ. Health Perspect. 2016, 124, 1344-1352. [CrossRef] [PubMed]

8. Kardan, O.; Gozdyra, P.; Misic, B.; Moola, F.; Palmer, L.; Paus, T.; Berman, M.G. Neighborhood greenspace and health in a large urban center. Sci. Rep. 2015, 5, 11610. [CrossRef] [PubMed]

9. Astell-Burt, T.E.; Feng, X.; Kolt, G. Is Neighborhood Green Space Associated With a Lower Risk of Type 2 Diabetes? Evidence From 267,072 Australians. Diabetes Care 2014, 37, 197-201. [CrossRef] [PubMed]

10. Dadvand, P.; Villanueva, C.; Font-Ribera, L.; Martinez, D.; Basagaña, X.; Belmonte, J.; Vrijheid, M.; Grazuleviciene, R.; Kogevinas, M.; Nieuwenhuijsen, M.J. Risks and Benefits of Green Spaces for Children: A Cross-Sectional Study of Associations with Sedentary Behavior, Obesity, Asthma, and Allergy. Environ. Health Perspect. 2014, 122, 1329-1335. [CrossRef]

11. Halonen, J.; Kivimaki, M.; Pentti, J.; Stenholm, S.; Kawachi, I.; Subramanian, S.; Vahtera, J. Green and blue areas as predictors of overweight and obesity in an 8-year follow-up study. Obesity 2014, 22, 1910-1917. [CrossRef]

12. Hartig, T.; Mitchell, R.; de Vries, S.; Frumkin, H. Nature and Health. Annu. Rev. Public Health 2014, 35, 207-228. [CrossRef] 
13. Maas, J.; Verheij, R.A.; Groenewegen, P.P.; De Vries, S.; Spreeuwenberg, P. Green space, urbanity, and health: How strong is the relation? J. Epidemiol. Community Health 2006, 60, 587-592. [CrossRef] [PubMed]

14. Chen, Y.; Yuan, Y. The neighborhood effect of exposure to blue space on elderly individuals' mental health: A case study in Guangzhou, China. Health Place 2020, 63, 102348. [CrossRef] [PubMed]

15. Gascon, M.; Zijlema, W.; Vert, C.; White, M.P.; Nieuwenhuijsen, M. Outdoor blue spaces, human health and well-being: A systematic review of quantitative studies. Int. J. Hyg. Environ. Health 2017, 220, 1207-1221. [CrossRef] [PubMed]

16. Grellier, J.; White, M.P.; Albin, M.; Bell, S.; Elliott, L.; Gascon, M.; Gualdi, S.; Mancini, L.; Nieuwenhuijsen, M.; Sarigiannis, D.; et al. BlueHealth: A study programme protocol for mapping and quantifying the potential benefits to public health and well-being from Europe's blue spaces. BMJ Open 2017, 7, e016188. [CrossRef] [PubMed]

17. Levin, P.S.; Poe, M.R. Conservation for the Anthropocene Ocean: Interdisciplinary Science in Support of Nature and People; Academic Press: Salt Lake City, UT, USA, 2017.

18. Domegan, C.; McHugh, P.; Devaney, M.; Duane, S.; Hogan, M.; Broome, B.J.; Layton, R.A.; Joyce, J.; Mazzonetto, M.; Piwowarczyk, J. Systems-thinking social marketing: Conceptual extensions and empirical investigations. J. Mark. Manag. 2016, 32, 1123-1144. [CrossRef]

19. Bell, S.L.; Phoenix, C.; Lovell, R.; Wheeler, B.W. Seeking everyday Wellbeing: The coast as a therapeutic landscape. Soc. Sci. Med. 2015, 142, 56-67. [CrossRef] [PubMed]

20. Depledge, M.H.; Harvey, A.J.; Brownlee, C.; Frost, M.; Moore, M.N.; Fleming, L.E. Changing Views of the Interconnections Between the Oceans and Human Health in Europe. Microb. Ecol. 2013, 65, 852-859. [CrossRef]

21. Korpela, K.M.; Ylén, M.; Tyrväinen, L.; Silvennoinen, H. Favorite green, waterside and urban environments, restorative experiences and perceived health in Finland. Health Promot. Int. 2010, 25, 200-209. [CrossRef]

22. Wheeler, B.W.; Lovell, R.; Higgins, S.L.; White, M.P.; Alcock, I.; Osborne, N.J.; Husk, K.; Sabel, C.E.; Depledge, M.H. Beyond greenspace: An ecological study of population general health and indicators of natural environment type and quality. Int. J. Health Geogr. 2015, 14, 1-17. [CrossRef]

23. Gianfredi, V.; Buffoli, M.; Rebecchi, A.; Croci, R.; Oradini-Alacreu, A.; Stirparo, G.; Marino, A.; Odone, A.; Capolongo, S.; Signorelli, C. Association between Urban Greenspace and Health: A Systematic Review of Literature. Int. J. Environ. Res. Public Health 2021, 18, 5137. [CrossRef]

24. van den Berg, M.; Wendel-Vos, W.; van Poppel, M.; Kemper, H.; van Mechelen, W.; Maas, J. Health benefits of green spaces in the living environment: A systematic review of epidemiological studies. Urban For. Urban Green. 2015, 14, 806-816. [CrossRef]

25. Lachowycz, K.; Jones, A.P. Greenspace and obesity: A systematic review of the evidence. Obes. Rev. 2011, 12, e183-e189. [CrossRef]

26. Owen, C.G.; Nightingale, C.; Rudnicka, A.; Sattar, N.; Cook, D.; Ekelund, U.; Whincup, P. Physical activity, obesity and cardiometabolic risk factors in 9- to 10-year-old UK children of white European, South Asian and black African-Caribbean origin: The Child Heart And health Study in England (CHASE). Diabetologia 2010, 53, 1620-1630. [CrossRef] [PubMed]

27. Hooper, P.; Foster, S.; Edwards, N.; Turrell, G.; Burton, N.; Giles-Corti, B.; Brown, W.J. Positive HABITATS for physical activity: Examining use of parks and its contribution to physical activity levels in mid-to older-aged adults. Health Place 2020, 63, 102308. [CrossRef] [PubMed]

28. Wood, L.; Hooper, P.; Foster, S.; Bull, F. Public green spaces and positive mental health-investigating the rela-tionship between access, quantity and types of parks and mental wellbeing. Health Place 2017, 48, 63-71. [CrossRef] [PubMed]

29. Lovell, R.; Wheeler, B.W.; Higgins, S.L.; Irvine, K.N.; Depledge, M.H. A Systematic Review of the Health and Well-Being Benefits of Biodiverse Environments. J. Toxicol. Environ. Health Part B 2014, 17, 1-20. [CrossRef]

30. de Keijzer, C.; Bauwelinck, M.; Dadvand, P. Long-term exposure to residential greenspace and healthy ageing: A systematic review. Curr. Environ. Health Rep. 2020, 7, 65-88. [CrossRef] [PubMed]

31. Akaraci, S.; Feng, X.; Suesse, T.; Jalaludin, B.; Astell-Burt, T. A systematic review and meta-analysis of asso-cia-tions between green and blue spaces and birth outcomes. Int. J. Environ. Res. Public Health 2020, 17, 2949. [CrossRef] [PubMed]

32. Islam, M.Z.; Johnston, J.; Sly, P.D. Green space and early childhood development: A systematic review. Rev. Environ. Health 2020, 35, 189-200. [CrossRef]

33. Davis, Z.; Guhn, M.; Jarvis, I.; Jerrett, M.; Nesbitt, L.; Oberlander, T.; Sbihi, H.; Su, J.; van den Bosch, M. The association between natural environments and childhood mental health and development: A systematic review and as-sessment of different exposure measurements. Int. J. Hyg. Environ. Health 2021, 235, 113767. [CrossRef] [PubMed]

34. Yuan, Y.; Huang, F.; Lin, F.; Zhu, P. Green space exposure on mortality and cardiovascular outcomes in older adults: A systematic review and meta-analysis of observational studies. Aging Clin. Exp. Res. 2021, 33, 1783-1797. [CrossRef] [PubMed]

35. Chang, P.-J. Effects of the built and social features of urban greenways on the outdoor activity of older adults. Landsc. Urban Plan. 2020, 204, 103929. [CrossRef]

36. Yang, Y.; He, D.; Gou, Z.; Wang, R.; Liu, Y.; Lu, Y. Association between street greenery and walking behavior in older adults in Hong Kong. Sustain. Cities Soc. 2019, 51, 101747. [CrossRef]

37. Zhu, A.; Yan, L.L.; Wu, C.D.; James, P.; Zeng, Y.; Ji, J.S. Residential greenness, activities of daily living, and in-strumental activities of daily living: A longitudinal cohort study of older adults in China. Environ. Epidemiol. 2019, 3, e065. [CrossRef] 
38. Dalton, A.M.; Jones, A.P.; Sharp, S.J.; Cooper, A.J.M.; Griffin, S.; Wareham, N.J. Residential neighbourhood green-space is associated with reduced risk of incident diabetes in older people: A prospective cohort study. BMC Public Health 2016, 16, 1117. [CrossRef] [PubMed]

39. Gharaveis, A. A systematic framework for understanding environmental design influences on physical activity in the elderly population. Facilities 2020, 38, 625-649. [CrossRef]

40. Wen, C.; Albert, C.; Von Haaren, C. The elderly in green spaces: Exploring requirements and preferences concerning nature-based recreation. Sustain. Cities Soc. 2018, 38, 582-593. [CrossRef]

41. Nutsford, D.; Pearson, A.L.; Kingham, S.; Reitsma, F. Residential exposure to visible blue space (but not green space) associated with lower psychological distress in a capital city. Health Place 2016, 39, 70-78. [CrossRef]

42. Völker, S.; Kistemann, T. The impact of blue space on human health and well-being-Salutogenic health effects of inland surface waters: A review. Int. J. Hyg. Environ. Health 2011, 214, 449-460. [CrossRef]

43. Britton, E.; Kindermann, G.; Domegan, C.; Carlin, C. Blue care: A systematic review of blue space interventions for health and wellbeing. Health Promot. Int. 2020, 35, 50-69. [CrossRef]

44. Yamashita, S. Perception and evaluation of water in landscape: Use of Photo-Projective Method to compare child and adult residents' perceptions of a Japanese river environment. Landsc. Urban Plan. 2002, 62, 3-17. [CrossRef]

45. Wyles, K.J.; Pahl, S.; Holland, M.; Thompson, R.C. Can Beach Cleans Do More Than Clean-Up Litter? Comparing Beach Cleans to Other Coastal Activities. Environ. Behav. 2017, 849, 509-535. [CrossRef] [PubMed]

46. Curtis, J.; Hynes, S. Demand for Water-Based Leisure Activity: The Benefits of Good Water Quality; Report (232); EPA, Johnstown Castle, Co.: Wexford, Ireland, 2017.

47. Steinwender, A.; Gundacker, C.; Wittmann, K.J. Objective versus subjective assessments of environmental quality of atanding and running waters in a large city. Landsc. Urban Plan. 2008, 84, 116-126. [CrossRef]

48. Karmanov, D.; Hamel, R. Assessing the restorative potential of contemporary urban environment(s): Beyond the nature versus urban dichotomy. Landsc. Urban Plan. 2008, 86, 115-125. [CrossRef]

49. Assmuth, T.; Hellgren, D.; Kopperoinen, L.; Paloniemi, R.; Peltonen, L. Fair blue urbanism: Demands, obstacles, opportunities and knowledge needs for just recreation beside Helsinki Metropolitan Area waters. Int. J. Urban Sustain. Dev. 2017, 9, 253-273. [CrossRef]

50. Paloniemi, R.; Niemelä, J.; Soininen, N.; Laatikainen, T.; Vierikko, K.; Rekola, A.; Viinikka, A.; Yli-Pelkonen, V.; Assmuth, T.; Kopperoinen, L.; et al. Environmental justice for the governance of aquatic environments. Local Environ. 2017, 23, 366-377. [CrossRef]

51. Pitt, H. Muddying the waters: What urban waterways reveal about blue spaces and wellbeing. Geoforum 2018, 92, 161-170. [CrossRef]

52. Eurofound. European Quality of Life Survey 2016: Quality of Life, Quality of Public Services and Quality of Society; Publications Office of the European Union: Luxembourg, 2017.

53. Northridge, M.E.; Stover, G.N.; Rosenthal, J.E.; Sherard, D. Environmental Equity and Health: Understanding Complexity and Moving Forward. Am. J. Public Health 2003, 93, 209-214. [CrossRef]

54. Rigolon, A.; Gibson, S. The role of non-governmental organizations in achieving environmental justice for green and blue spaces. Landsc. Urban Plan. 2021, 205, 103970. [CrossRef]

55. Mushangwe, S.; Astell-Burt, T.; Steel, D.; Feng, X. Ethnic inequalities in green space availability: Evidence from Australia. Urban For. Urban Green. 2021, 64, 127235. [CrossRef]

56. Wolch, J.R.; Byrne, J.; Newell, J. Urban green space, public health, and environmental justice: The challenge of making cities 'just green enough'. Landsc. Urban Plan. 2014, 125, 234-244. [CrossRef]

57. Rigolon, A.; Németh, J. Green gentrification or 'just green enough': Do park location, size and function affect whether a place gentrifies or not? Urban Stud. 2019, 57, 402-420. [CrossRef]

58. Park, Y.; Guldmann, J.-M. Understanding disparities in community green accessibility under alternative green measures: A metropolitan-wide analysis of Columbus, Ohio, and Atlanta, Georgia. Landsc. Urban Plan. 2020, 200, 103806. [CrossRef]

59. Mullenbach, L.E.; Baker, B.L.; Benfield, J.; Hickerson, B.; Mowen, A.J. Assessing the relationship between community engagement and perceived ownership of an urban park in Philadelphia. J. Leis. Res. 2019, 50, 201-219. [CrossRef]

60. Pearsall, H.; Eller, J.K. Locating the green space paradox: A study of gentrification and public green space ac-cessibility in Philadelphia, Pennsylvania. Landsc. Urban Plan. 2020, 195, 103708. [CrossRef]

61. Badham, J.; Chattoe-Brown, E.; Gilbert, N.; Chalabi, Z.; Kee, F.; Hunter, R.F. Developing agent-based models of complex health behaviour. Health Place 2018, 54, 170-177. [CrossRef] [PubMed]

62. Mittelstaedt, J.D.; Shultz, C.J.; Kilbourne, W.E.; Peterson, M. Sustainability as megatrend: Two schools of macromarketing thought. J. Macromarketing 2014, 34, 253-264. [CrossRef]

63. Scharmer, O.; Kaufer, K. Leading from the Emerging Future, from Ego-System to Eco-System Economics; BK Currents Book: Oakland, CA, USA, 2013.

64. Ii, C.J.S.; Rahtz, D.; Sirgy, M.J. Distinguishing Flourishing from Distressed Communities: Vulnerability, Resilience and a Systemic Framework to Facilitate Well-Being. In Handbook of Community Well-Being Research; Springer: Berlin/Heidelberg, Germany, 2017; pp. 403-421. 
65. Domegan, C.; Kindermann, G.; Brolcháin, N.Ó.; Britton, E.; Carlin, C.; Osagie, E.; O’Loughlin, M.; Cormican, M.; Donovan, F.; Mulcahy, M.; et al. Our Environment, Our Health, Our Wellbeing: Access to Blue/Green Spaces in Ireland; Environmental Protection Agency: Wexford, Ireland, 2021.

66. Grilli, G.; Mohan, G.; Curtis, J. Public park attributes, park visits, and associated health status. Landsc. Urban Plan. 2020, 199, 103814. [CrossRef]

67. Dempsey, S.; Devine, M.T.; Gillespie, T.; Lyons, S.; Nolan, A. Coastal blue space and depression in older adults. Health Place 2018, 54,110-117. [CrossRef]

68. Kindermann, G.; Domegan, C.; Duane, S. COVID-19 and Sheer Wellbeing Access to and Use of Blue/Green Spaces in Ireland during a Pandemic; Environmental Protection Agency: Wexford, Ireland, 2020.

69. Langellier, B.A.; Yang, Y.; Purtle, J.; Nelson, K.L.; Stankov, I.; Roux, A.V.D. Complex Systems Approaches to Understand Drivers of Mental Health and Inform Mental Health Policy: A Systematic Review. Adm. Policy Ment. Health Ment. Health Serv. Res. 2018, 46, 128-144. [CrossRef]

70. Wolstenholme, E.F. Qualitative vs Quantitative Modelling: The Evolving Balance. J. Oper. Res. Soc. 1999, 50, 422-428. [CrossRef]

71. Taylor, L.; Hochuli, D.F. Defining greenspace: Multiple uses across multiple disciplines. Landsc. Urban Plan. 2017, 158, 25-38. [CrossRef]

72. European Commission (EC). Attitudes of European Citizens towards the Environment. Special Eurobarometer 468; Publications Office of the European Union: Luxembourg, 2017.

73. Natural England (NE). Monitor of Engagement with the Natural Environment: Survey Purpose and Results. Natural England: Peterborough, UK, 2018. Available online: http://naturalengland.etraderstores.com/NaturalEnglandShop/product.aspx (accessed on 13 December 2019).

74. Hastings, G.; Domegan, C. Social Marketing: Rebels with a Cause; Routledge: Abingdon, UK, 2017.

75. Ricigliano, R. Making Peace Last: A Toolbox for Sustainable Peacebuilding; Routledge: Abingdon, UK, 2015.

76. Sterman, J. Business Dynamics: Systems Thinking and Modelling for a Complex World; Irwin/McGraw-Hill: Boston, MA, USA, 2000.

77. Warfield, J.N.; Cárdenas, A.R. A Handbook of Interactive Management; Iowa State University Press: Ames, IA, USA, $1994 ;$ p. 338.

78. Layton, R.A. Formation, Growth, and Adaptive Change in Marketing Systems. J. Macromark. 2015, 35, 302-319. [CrossRef]

79. Mohr, J.; Mohr, R. Kumu (Personal Version). 2011. Available online: https:/ / kumu.io (accessed on 28 July 2021).

80. Morales, A.C.; Amir, O.; Lee, L. Keeping It Real in Experimental Research-Understanding When, Where, and How to Enhance Realism and Measure Consumer Behavior. J. Consum. Res. 2017, 44, 465-476. [CrossRef]

81. Galizzi, M.M.; Navarro-Martinez, D. On the External Validity of Social Preference Games: A Systematic Lab-Field Study. Manag. Sci. 2019, 65, 976-1002. [CrossRef]

82. Rud, O.P. Business Intelligence Success Factors: Tools for Aligning Your Business in the Global Economy; John Wiley \& Sons: Hoboken, NJ, USA, 2009.

83. Layton, R. Marketing Systems—Looking Backward, Sizing up and Thinking Ahead. J. Macromark. 2019, 39, 208-224. [CrossRef]

84. Layton, R.A. Towards a theory of marketing systems. Eur. J. Mark. 2011, 45, 259-276. [CrossRef]

85. Badejo, F.A.; Rundle-Thiele, S.; Kubacki, K. Taking a wider view. J. Soc. Mark. 2019, 9, 467-484. [CrossRef]

86. Wilson, D.S. This View of Life: Completing the Darwinian Revolution; Pantheon Books: New York, NY, USA, 2019.

87. Wooliscroft, B. Macromarketing and the Systems Imperative. J. Macromark. 2021, 41, 116-123. [CrossRef]

88. Oliva, R.; Mojtahedzadeh, M. Keep it simple: Dominance assessment of short feedback loops. In Proceedings of the 22nd International System Dynamics Society Conference, Oxford, UK, 25-29 July 2004; pp. 25-29.

89. United Nations (UN) General Assembly. Universal Declaration of Human Rights. (217 [III] A). Paris, 1948. Available online: www.un.org/en/universal-declaration-human-rights / (accessed on 6 December 2020).

90. United Nations (UN) General Assembly. International Covenant on Economic, Social and Cultural Rights. United Nations, Treaty Series. 1966, Volume 993, p. 3. Available online: https://www.refworld.org/docid/3ae6b36c0.html (accessed on 7 December 2020).

91. United Nations (UN) General Assembly. Transforming our World: The 2030 Agenda for Sustainable Development. A/RES/70/1. 21 October 2015. Available online: www.refworld.org/docid/57b6e3e44.html (accessed on 7 December 2020). 